\title{
Investigating the various models and viewpoints of the corporates social responsibilities
}

\author{
Majid Moradi ${ }^{1 *}$, Zohreh Sayyad ${ }^{2}$ \\ ${ }^{1}$ Faculty of Accounting, Department of Naser Khosro Institute of Higher Education of Saveh, Saveh, Iran \\ ${ }^{2}$ Naser Khosro Institute of Higher Education of Saveh, Saveh, Iran
}

\author{
Keywords \\ Social responsibility \\ Global trade \\ Profitability \\ Environmental issues \\ Received: 13 May 2020 \\ Accepted: 22 July 2020 \\ Published: 20 October 2020
}

\begin{abstract}
Corporates Social Responsibility (CSR) and the role of the business units have expanded in society along with global trade development. In addition, significant international development has occurred in the CSR movements, and this development is observable in the research evolution of CSR transparently. This research aims at assessing the viewpoints and models of the concept of social responsibilities. This research is applied according to the fundamental objective, is research-based on its nature, and the data collection method is the librarian. The research findings showed that according to the financial collapse and scandal of some companies such as Enron at the beginning of the 21st century, discussion about the rank of CSR in the global economy, particularly the international corporates, has increased to improve the social and environmental conditions. The objective of corporates is to increase efficiency and profit. Negligence to the social and environmental issues and similar cases makes problems for the corporate and undoubtedly influences the activities and mission of the corporate, as well as its success. It is recommended to the manufacturing corporates to search for the root changes of this factor in other factors and know that if other facilities and conditions of social responsibility are tracked correctly, this factor will go on effectively along with the social responsibility.
\end{abstract}

(c) 2020 The Author(s). Published by TAF Publishing.

\section{INTRODUCTION}

Corporates report their social responsibilities and environmental and social effects. Reporting can improve a corporate's ability to integrate indexes of social responsibility, lasting with their business, the process of decision-making, and identifying risks and opportunities. Reporting the indexes of social responsibility and lasting can act as a tool to change the external perception and stimulating domestic and foreign shareholders in the corporate. Honest, relevant, and complete reporting of the indexes of social responsibility and lasting increase the employees' motivation, improves fame or commercial brand of corporate, increases credit, and makes competitive advantage. Moreover, web-based reporting provides the indexes of social responsibility and lasting of the flexibility opportunities to provide data and the reciprocal reaction of shareholders, and varied connectivity (Eisaei \& Yahyapour, 2013). Corpo- rate social responsibility is a developing concept that is perceived as a method in which corporates integrate their social, environmental, and economic concerns in values, cultures, decisions, strategy, and operations transparently to respond. As a result, they make better procedures, welfare, and improvement of society (Turker, 2009). Lee and Bruvold (2003) says that CSR is a conceptual umbrella with varied and completely related terminology. This refers to the environment and society and mentions parameters about the social role of corporates with a transparent, responsive, and lasting language by a multi-dimension and commercial approach. Actually, the issue that corporates are responsible for a wide range of stakeholders beyond the shareholders is in the gravity center of the concept of corporates social responsibilities.

* corresponding author: Majid Moradi

†email:m.moradi@hnkh.ac.ir 


\section{Problem Statement}

CSR is an essence that corporates should be responsible not only for their shareholders, but also for the other stakeholders such as their creditors, retailers, and most importantly their customers (Brammer, Millington, \& Rayton, 2007; Wasike, 2017). The importance of social responsibility emphasizes that each corporate not only should follow the laws but also should make this motivation in itself to act the social responsibility. Although social responsibility originates from the western world, it has a deep root in China's history and has been accepted significantly by corporates and legislators. Moreover, Colbert, Wheeler, and Freeman (2003) noted that social responsibility provides some regulations for corporates about social responsibility. Moradi (2016) explained social responsibility as the corporates' managers' job are challenged for quick sophistication of business place, and stockholders justify managers to make desirability in the corporate, and this activity will be possible according to the corporate social responsibility. The term corporates social responsibility refers to an arrival of a movement which tracks entering the social and environmental factors in the commercial decisions of corporates, commercial strategies, and accounting to increase social and environmental performance beside the economic dimensions in a way that will be useful for a business unit, society, and the environment (Thang \& Fassin, 2017). Although the concept of corporates social responsibility has been extensively discussed in the theory and practice, it hasn't been offered a public accepted concept (Turker, 2009).

On the other hand, one of the important attitudes of people toward the job which influences their behavior in the organization and can be important for the managers of the organization is the organizational trust and commitment. Organizational commitment is a state that an employee knows the employing organization as his/her introducer and defines the organizational trust as the positive expectations of people based on the organizational roles, relations, experiences, reciprocal attachments of intentions, and various behaviors of the organization members. In addition, Ferris (2008) defines the organizational trust as one party's tendency to be vulnerable to the other party based on the expectation or belief that the other party is safe, open, and trustworthy.

Social responsibility is one of the most important elements of the essence of the philosophy of organizations in a way that emphasizing its observance by the organizations not only makes the promotion of organizational commitment possible but also reinforces the satisfaction of the stake- holders out of the organizations to legitimize the organization. The effective factors that should be mentioned in each organization along with the organizational commitment of employees are social responsibility and social capital. Meanwhile, making networks and communication channels, and a way to increase the responsibility of employees can increase the organizational commitment of employees (Ardalan, Ghanbari, Beheshtirad, \& Navidi, 2015). Lee and Bruvold (2003) studied about CSR and decision in the supply chain by the government subsidies. The relevant social issues have become more significant than past by the quick economic development.

The effective appraising manner of corporates to have more CSR and protecting the society's sustainable development is an emergent duty of the managers and researchers to solve the social issues. A three-step Stackelberg game model is formed for supply chain decision issues dominated by retailers, by considering CSR under government subsidies, and based on the game-based analysis technic which includes government, prior retailers, and suppliers. This is used to analyze the optimum decisions with the government subsidies and studies the effect of government subsidies on the profit of supply chain members, attempt level of CSR, and social welfare in the dominated supply chain by retailers, as well as determining the relationship between the optimal government subsidy rates, and CSR level. These results showed that higher attempts will have higher effects on the profit of all items in the supply chain. A great spectrum of the government subsidies can move the supply chain members toward CSR and general performance improvement of social welfare and supply.

Ferrell, Harrison, Ferrell, and Hair (2019) studied business ethics, CSR, and brand attitudes. The perception of the relative importance of business ethics and social responsibility is important in the determination of brand attitudes. Nonetheless, there were shortcomings in distinguishing between attitudes toward business ethics and CSR in the previous literature. This research examines the relevant studies to brand-customer about business ethics and social responsibility and researched to assess the customer's attitudes. They offered four scenarios about changes in the related corporate behaviors to the negative and positive behaviors of customer social responsibility and business ethics. The obtained results from a 351-member panel study provide a new viewpoint about the customer's expectations, CSR perception, and business ethics. It is concluded that CSR attitudes can be still important; nonetheless, customers consider business ethics as the most important behavior in their perception of the brand attitude. 
Cho, Lee, and Pfeiffer Jr (2013) studied CSR and information asymmetry. It is found that both negative and positive scores of CSR performance using the CSR performance information collected by KLD provide data that reduces information asymmetry. The extra tests show that the negative performance of CSR has more effect on the suggested price range differences of buyer and seller than the positive performance of CSR. This document suggests that future studies about capital markets should prevent working by pure scores to prevent a lack of existed information in scores of the main elements. Then, a positive and important relationship between the suggested price range difference of the buyer and seller, institutional ownership exchange, and CSR activities is found that says institutional investors with the private CSR performance data seem to use the advantage of this data which reduces the information asymmetry. James (2016) studied the mutual interactions and CSR as pieces of evidence of the Zambia Copper Mining Department. This research detected a serious inconsistency in the relationships between government, civil society, and mineral corporates that are intensified by various factors such as the classification of the main stakeholders. Despite the power imbalance of stakeholders, the creative cooperation power at the local level has faced challenges for lack of accepted environmental and social frameworks, transparency, and responsibilitytaking of the stakeholders. Nonetheless and despite this inconsistency, some limited activities become possible such as civil society accepting the past inactive stakeholders for cooperation to show its priority and reinforces the government. This research studies these issues in one of the main industries of Zambia, the copper mining department, that economy is so dependent on it.

Cho et al. (2013) studied CSR and information asymmetry. It is found out by CSR performance information that was collected by KLD that both negative and positive scores of CSR performance seem to provide information that reduces information asymmetry. The extra tests show that the negative performance of CSR has more effect on the suggested price range difference of the buyer and seller than the positive performance of CSR. This document suggests that future studies in the capital market issues should prevent working with pure scores to prevent a lack of the existed information in the scores of the main elements. Then, a positive and important relationship between the suggested price range differences of buyer and seller and the expression of institutional ownership exchange, and CSR activities is found that says institutional investors with the private CSR performance information seem that use the advantage of this information in a way to reduce the lack of informa- tion symmetry.

\section{The Necessity and Importance of Research}

Corporate social responsibility is an emerging movement in corporates that seeks a useful and effective solution to face social and environmental issues of modern corporates in today's society. Acceptance and adaptation motives with social responsibility in much new literature and research are mentioned by researchers and academics, and this research can help to a better perception of social and environmental plans of corporates as a profitability motive and proper performance in the society. Criticism of modern corporates and the fundamental problems of the current global economic system can prevent the advent of any sustainable development. Therefore, the moldering process of corporates should be balanced with the social and environmental concerns, and corporates social responsibility can be used as a conceptual umbrella to remove the contradictions and conflicts in modern corporates, society, and expectations of stakeholders because profit sustainability is provided in this way. In addition, the societies' expectations in ethical, legal, economic, and public interests of organizations are to be committed to the society they act. In this regard, when the issue of social responsibility in the social life such as organizations is analyzed, only the right of stockholders, establishers, or even obeying the legal frameworks, which are compulsory, should not be considered as the act criteria of the organization. Instead, responsibility should be considered as a voluntary matter, type of commitment, and task by organizations (Ghasemi Ali Abadi, Shakeri, \& Nassiri Aghdam, 2017; Lopacinska, 2016).

Geva (2008) examined the manufacturing corporates social responsibility. Despite having the main literature in CSR, this expression is still vague and discussable based on meaning, application, and usefulness. Specifically, the effect of CSR on the tangible and intangible returns of Chinese manufacturers is unknown. An exploratory classification of CSR methods in China manufacturing industries is developed using stakeholder theory and CSR literature empirically. Three CSR classification were identified by studying active manufacturers in the food, pharmaceutical, automobile, and apparel industries of China, and their relationships with their financial, operational, reputation, and social performance. These findings deepen the CSR binding patterns perceptions by clarifying the consequences of CSR acceptance in China manufacturing industry. 


\section{SOCIAL RESPONSIBILITY VIEWPOINTS}

\section{Classic Viewpoint}

Based on this viewpoint, the organization should seek its benefits and does not have any activity directly about objectives and social issues. Social responsibility is defined as the production of goods and services at the lowest cost to society under these conditions. One of the strongest fans of the classic viewpoint is Milton Fraidman. This well-known economist believes that managers should have the type of activities to maximize the profit of stockholders. Fraidman believes that it is wrong to allocate the organization's resources to social programs without the consent of stockholders. In addition, he believes that the social responsibility of economic agencies is gaining profit. In this case, Robert Merser, a fan of classic viewpoint, says "the main responsibility of each economic agency is getting profit. It means that neither you nor ant employees or anyone else should not think to society. It's they look selfish. Do not forget that getting profit is like getting oxygen. If it does not obtain in time, you will die and no one else can do anything for you. When an organization gets profit to guarantee its life, then it can do its other responsibilities "(Alvani \& Ghasemi, 2013).

\section{Accountability Viewpoint}

Based on this view, managers should have a sense of responsibility (be accountable) toward the specific effective groups on the organization or the ones who can influence the resources or objectives of the organization. In other words, an economic agency should have a sense of accountability not only toward its stockholders and capitalists but toward the involved groups in its success equally. These groups include stockholders, customers, governmental organizations, labor unions, employees, raw material suppliers, creditors, and so on. In other words, the economic institutions based on the accountability viewpoint not only should try to protect capital and to increase their profit but also have a sense of responsibility to the involved groups in their attempts (Alvani \& Ghasemi, 2013).

\section{Public Viewpoint}

This view has a wider scope than the view of responsibility. The public viewpoint defined the economic agencies as the partners of government and other social institutions (such as education organization) and believes that organization has to solve the problem of society and improve the living quality of all people besides the other public institutes. As a result, profitability is considered as only one of the objectives of the economic agency. Therefore, the organiza- tion is not free only to persuade its objectives. According to this viewpoint, an organization is committed to following its objectives as much as the humanitarian goals. In this regard, the organization seriously tries to eliminate public problems such as poverty, pollution, inflation, etc. The fans of this philosophy believe that the organization must consider itself indebted to society and always consider itself as its servant because society lets the organization act and use its scarce resources and make the proper environment to get profit for it.

\section{RESEARCH METHODOLOGY}

The objectives of all sciences are cognition and perception of the surrounding world. The scientific methods have changed significantly to be aware of the issues and problems of the social world. These trends and movements have led to the use of scientific methods to study various human disciplines. The characteristics of the scientific study to find the truth is a proper research method, and selecting a proper research method depends on the objectives, nature, and subject of the research, and the executive facilities. In addition, the research aims to access precisely and easily to answer the research questions. The methodology of this research is actually a strategy encompassing philosophical assumptions of the research design as well as data collection. In this research, tracking the qualitative paradigm was inevitable because of the lack of research based on social responsibility and the need to identify how to determine phenomenon in the real condition. On the other hand, the need to purify the factors, determine the model, and examine the model, elements, and relationships descriptively required the use of qualitative methods. Data theory is one of the well-known methods of qualitative research that was introduced by Donaldson and Preston (1995) for the first time. Researchers use this method usually when their subject was neglected in previous studies or has been mentioned superficially. It means this method is used when the research aims to code, moderate, or to modify a theory. The specific characteristic of this research is that theoretical assumptions are not stated at the beginning of the study, but the generalizations (theory) are emerged by data. In this method, the big samples are used instead of collecting data suddenly for analysis beyond description, new classifications beyond previously perceived ideas, and iterative analysis of data. In summary, the analysis process and formulation of the theoretical issues are emphasized in this method instead of the sole focus on the research findings. 


\section{MODELS OF CSR}

\section{Caroll's CSR Pyramid Model}

CSR is made of 4 parts of economic (getting profit), legal (based on laws), ethical (ethics), and philanthropic (good citizen) (Lau, Lee, \& Cheng, 2018). In this model, the economic responsibilities are the main responsibilities of an organization which is profitability. The legal responsibilities refer to that organization should act in its laws and comprehensive regulations framework of economic activity. The third responsibility of corporates is ethical by which the corporates are expected to consider and respect the norms and values of society. Finally, the philanthropic responsibilities refer to the voluntary activities of corporate (Alvani \& Ghasemi, 2013). The components of the social responsibility model are hierarchically decreasing in importance. In this regard that legal responsibility is considered as the basis and all other responsibilities refer to economic responsibility, and corporates are expected to act in the legal framework. Thus, legal responsibility is the next layer of the pyramid. Later, ethical responsibility is proposed. Philanthropic responsibility is at the peak of this pyramid and is voluntary with the minimum importance. In this regard, the more approaching to the peak of the pyramid, the less the components are important (Lau et al., 2018).

\section{Crossover Model}

Caroll's pyramid model can't protect the realm nature of CRS completely and fully illustrate the interrelationships between them. The realms of CSR have interacted and one of the inseparable characteristics of CSR is reciprocal communication. In this regard, the crossover model says that various responsibilities have dynamic and reciprocal relationships with each other. Particularly, economic responsibility is not the most principal and economic activity along with CSR u less important than others. Alternatively, legal, ethical, and philanthropic responsibilities are as important as the economic responsibility for business (Brammer et al., 2007).

\section{Concentrated Range Derives}

This model is similar to the pyramid model that the economic role of business from one aspect is the main core of social responsibility. Moreover, it is similar to the crossover model that mentions the reciprocal relationships between the CSR realms. In this way that economic responsibilities are at the center of this model like Caroll's pyramid model, but not more important than other realms. On the contrary, philanthropic responsibilities are the most important but this should be done in the economic realm. In this model, each member of the internal circle is the member of the more-extended external circle, but this relation is not vice versa (Brammer et al., 2007).

\section{Various Approaches to the Concept of CSR}

Generally, there are 3 approaches to the concept of CSR as follows:

- First theory: it originates from the economic classic theories. According to this concept, the corporate has only and only one objective and that is maximizing profit and consequently maximizing the stockholders' wealth. Of course, this concept is accepted and supported to the extent to be in an attempt to reach a legal and ethical framework.

- Second theory: it was provided in the 1970s by which social objectives are mentioned according to maximizing the profit. According to this theory, corporates managers should make decisions to balance the rights of stockholders, employees, customers, and the public. As a result, a correlation and coalition should be between multiple interests and considerations, and this coalition is the only way to ensure the objective of profit-maximizing in the long-term.

- Third theory: according to the third theory, the profit is not the end of the institutes, and the executive managers of corporates after getting profit face with the problems of employees' demands for a salary increase, the necessity of executing the development plans, ask for lower prices by customers, and higher stock profit for stockholders. In this case, organizational decisions seek to achieve an appropriate level during which both profits are achieved and a desirable level of social goals is provided instead of trying to maximize profits.

Changing from the second to the third theory of social responsibility of institutes, similar to movement from the concept of commercial institutes based on the stockholders' profit, is a more extensive concept. It means the criterion in the second theory is bringing profit for stockholders which are related to the right of the other interested groups such as customers, employees, etc. However, the third theory emphasizes that the commercial institutes are stakeholders from people and loss and profit are the result of their activities, and the organizational decisions should be made based on the group of policies that make more responsibility in society. Most institutes are not often able to plan in affairs that the majority use them. Thus, most ideas in this field are caused by mental judgments in this field. In this way, reaching social and economic well-being based on theory and mentality may not lead to useful decisions for society (Forughi, Mirshams, \& Pourhossein, 2008). 
THE POPULAR THEORIES IN THE LITERATURE OF CRS Theory of Legitimacy

Historically, organizations have remained sustainable by the approach of profit production for stockholders. Nonetheless, this approach is not enough to guarantee survival today. In the modern world, organizations should gain the society's satisfaction for survival in any market and size, and this satisfaction is obtained only when the societies believe that organizations' operations influence humans and the environment usefully. Ordinary people, potential investors, politicians, and an extensive range of other stakeholders know organizations responsible for the social, environmental, and economic effects. 3 dimensions of social responsibility include social, environmental, and economic dimensions encompass people, earth, and profit, respectively. The theory of legitimacy assumes that organizations seek insurance about their activities to be legitimated by the society permanently. Legitimacy is actually a generalized concept that the acts of each economic unit are proper, desired, and appropriate to the norms, values, and beliefs in a social system, and organizations want to act in the framework of the society's norms. As ethical and subjective values change over time, organizations are expected to respond to these changes. In this case, legitimacy means the adaptation of each economic unit with the current condition in a social system based on its values and norms (Ali, 2012). The theory of legitimacy assumes that an organization has a social contract with a society where it acts. The concept of "social contract" is community expectations about the operations and activities of any organization. Undoubtedly, the expectations of society in recent decades have significantly changed, and corporates should mention the human, environmental, and social effects of their activities and have good reactions to them to fulfill these new expectations. If organizations fail to consider this concept of "social contract", they may be deprived by society. Actually, losing the legitimacy of corporates from society's viewpoint makes problems, limitations, and many obstacles. As a result, even the goal of maximization of their profit will not be accomplished as an absolute performance according to the stockholders' viewpoint (Eisaei \& Yahyapour, 2013). The theory of legitimacy states that organizations can survive until society legitimizes them and gives them legitimacy. In other words, our social contract is between corporates and each member of society. Society, as a group of individuals, gives organizations the authority to use natural resources and labor. Organizations use these resources and influence the environments negatively besides providing services and goods. Legitimacy is a resource that the orga- nizations' survival depends on it. However, an organization can influence this resource or manipulate it. Alternatively, managers try at any rate to survive the organization to increase its legitimacy. Therefore, they use some strategies in this field. Some of these strategies include companion with the society's expectations, increasing the social resources of organization than it social costs, putting the value system of organization, distributing the political, economic, or social benefits in various groups of their organizational power channels, changing the organizational behaviors along with the change of society's expectation, persuading society members about the organization accountability, changing social expectation, perception, or values, reducing the conflicts in benefits of various stakeholders groups in the organization, changing the society's perception, taking their attention far from the concerning issues, and attracting their attention to the other issues. However, any taken strategy by a manager can influence the society if it is divulged and given to the public (Cho et al., 2013).

\section{Theory of Political Economy}

Today, the correct perception of the political role of corporates is essential beyond obeying the legal standards and ethical regulations to respond to the globalization phenomenon and challenges of the postmodern era. The globalization of the economy has created challenges to guide this path beyond the capacity of any government, and the distinction between political and economic activities of corporates in global governance does not make sense to solve this problem. Instead, the behavioral standards of corporates should be revised and in addition to economic considerations, the social, political, and environmental spaces should be considered to reach the social expectations. As a result, the current image of corporates' management in the political and social aspects is still vague. Hence, the theory landscape does not still have efficient accountability to these new challenges in the CSR issue. Therefore, desired interaction and cooperation between corporates and civil institutions can be considered a key factor for these issues for the perception of this conflict in economic and political approaches. In addition, the analysis of the new issue in political theory can be useful to solve these challenges and problems. The institutional theory approach of CSR refers that mutual decisions about CSR is not only a tool decision but consider more extensive social content. The global procedure shows that governments support the economy by scarifying the environment. Thus, corporates should consider the balance between the economic, social, and environmental elements as a vital matter to accomplish 
the concept of sustainable development. Moreover, the governments have to code the sever regulations in the environmental dimension to control economic activities without damaging the environment and social sustainability. There are two aspects in the theory of political economy: 1- classic, 2- medium class. The classic political economy claims that whenever divulging the related information to the social effect of a commercial unit activity is done voluntarily, only it satisfies a part of legitimacy. Thus, this view has a clear tendency to enact mandatory disclosure laws. In this viewpoint, the government is selected to impose restrictions on organizations. Thus, the government is responsible to protect the benefits of non-powered groups to protect the legitimacy of a system as a whole (Moradi, 2016).

\section{Stakeholders Theory}

Stakeholders' theory was developed gradually in the 1970 s. The stakeholders' approach emerged in the middle of the 1980s. The main point in this movement was publishing Richard Edward Frieman's work. The title of his work was strategy management where the stakeholder approach was proposed as a secondary issue in 1984 . He refereed that his look toward the stakeholder concept is based on the aspect of corporate (Fontaine, Haarman, \& Schmid, 2006). Frieman proposed the general theory of corporate and suggested two extensive groups for corporate accountability. Many studies have formed based on the stakeholder theory since then. The role of corporates in society has chronically attracted the attention of many people and has been the focus of discussion by influencing their employees, the environment, local communities, and shareholders. Stakeholder theory is combined by the social and organizational theories and is actually an extensive research test or a unit formal theory something less than a formal integrated theory and more than extensive research which mixes philosophy, law, ethics, and political, economics, and social science theory (Colbert et al., 2003). The basis of stakeholder theory is that corporates have grown so large and their impact on society is so deep that they have to pay attention and be accountable to fulfill their responsibilities to the greater parts of the society in addition to their shareholders. As a result, not only the stakeholders are impressed by corporates, but also they influence corporates by their way. Alternatively, corporate is a social unit that should be responsible for the more extensive factors than its owners (Eisaei \& Yahyapour, 2013). Stakeholders in the corporate do not have shares but they do have an interest. The stakeholders' relationship has been defined as an interaction where the stakeholder groups help corporates by their participa- tion, and it is predicted that their benefits are supplied by encouraging and motivating. The public can be considered as a corporate stakeholder by this analytical framework, because they provide the infrastructure for corporates to operate by paying taxes. In this transaction, expect corporates, as citizens, to promote the life quality (Donaldson \& Preston, 1995). Stakeholder theory is significantly important to improve the corporate strategies. The real influences between the corporate and stake the holders influence the corporate significantly in long-term. In this way, the weak relationship with stakeholders has negative effects on the performance of a corporate and brings bankruptcy of them (James, 2016). Stakeholders are in range of the minimum to maximum accountability for having the perceived relations that the stakeholder is an individual or a group than is interested in being the organization because he/she can influence or be impressed by it. Most stakeholders intending to be financial or commercial motives were reorganization's empirical studies. Generally, the organizations stakeholders are the ones that can both impressed on and influence the corporate. These groups mostly include investors, suppliers, employees, customers, competitors, local unions, and regulators. Stakeholders are valuable because they help the organization achieve its goals. Therefore, organization cannot be apathetic in coding and executing the various plans. In this regard, stakeholders' theory obliges organizations to pay attention to their demands in making operational and strategic decisions. The initial basis of this work is communication with them which forms another type of organizational relationship (Moradi, 2016).

\section{CONCLUSION AND IMPLICATIONS}

CSR is a new movement in corporates that tracks a useful and effective solution to face social and environmental issues of modern corporates in today's society. Acceptance and adaptation motives with social responsibility in much new literature and research are mentioned by researchers and academics at the corporate level, and this research can help to a better perception of social and environmental plans of corporates as a profitability motive and proper performance in the society. Criticism of modern corporates and the fundamental problems of the current global economic system can prevent the advent of any sustainable development. Therefore, the moldering process of corporates should be balanced with the social and environmental concerns, and CSR can be used as a conceptual umbrella to remove the contradictions and conflicts in modern corporates, society, and expectations of stakeholders because profit sustainability is provided in this way. In 
this research, social responsibility was first explained, and its various models and viewpoints were studied.

- One of the obtained suggestions by conducting this research to the manufacturing corporates is attention to the environmental conditions as an impressible factor. Therefore, notice that changing each component can change the environmental conditions.Thus, it is recommended to the manufacturing corporates to search for the root changes of this factor in other factors and know that if other facilities and conditions of social responsibility are tracked correctly, this factor will go on effectively along with the social responsibility.

- Education and culture-making of divulging social and environmental performance of corporates and providing essential motives to persuade corporates for more activity and participation as much as possible in this field by the relevant institutions for the lasting development and growth of the economic agencies

\section{REFERENCES}

Ali, a. F. A. J., I. (2012). Corporate social responsibility, corporate reputation and employee engagement (Unpublished master's thesis). Department of Management Sciences ,COMSATS, Institute of Information Technology, Lahore, Pakistan.

Alvani, S., \& Ghasemi, A. R. (2013). social management and responsibilities of organization. Tehran, Iran: Public Management Training Center.

Ardalan, M., Ghanbari, S., Beheshtirad, R., \& Navidi, P. (2015). The impact of social capital and social responsibility on organizational commitment. Journal of Measuring and Educational Evaluation Studies, 5(10), 109-132.

Brammer, S., Millington, A., \& Rayton, B. (2007). The contribution of corporate social responsibility to organizational commitment. The International Journal of Human Resource Management, 18(10), 1701-1719. doi:https://doi.org/10.1080/ 09585190701570866

Cho, S. Y., Lee, C., \& Pfeiffer Jr, R. J. (2013). Corporate social responsibility performance and information asymmetry. Journal of Accounting and Public Policy, 32(1), 71-83. doi:https://doi.org/10.1016/j.jaccpubpol.2012.10.005

Colbert, B., Wheeler, D., \& Freeman, R. (2003). Focusing on value: Reconciling corporate social responsibility, stakeholder theory and sustainability in a network world. Journal of General Management, 28(3), 1-28.

Donaldson, T., \& Preston, L. E. (1995). The stakeholder theory of the corporation: Concepts, evidence, and implications. Academy of Management Review, 20(1), 65-91. doi:https://doi.org/10.5465/amr.1995.9503271992

Eisaei, T. M., \& Yahyapour, J. (2013). Stakeholder theory with the approach of regulations of Iranian joint stock companies. Journal of the Stock Exchange, 23(6), 139-167.

Ferrell, O., Harrison, D. E., Ferrell, L., \& Hair, J. F. (2019). Business ethics, corporate social responsibility, and brand attitudes: An exploratory study. Journal of Business Research, 95, 491-501. doi:https://doi.org/10.1016/j.jbusres.2018.07.039

Ferris, W. P. (2008). Welcome to the first issue of OMJ on the palgrave macmillan platform. Organization Management Journal, 5(1), 1-12. doi:http://dx.doi.org/10.1057/omj.2008.10

Fontaine, C., Haarman, A., \& Schmid, S. (2006). The stakeholder theory. New York, NY: Sage Publications.

Forughi, D., Mirshams, S. M., \& Pourhossein, S. (2008). Managers' attitudes towards disclosure of social accounting information: Listed companies in Tehran stock exchange. Journal of Accounting and Auditing Reviews, 52(6), 55-70.

Geva, A. (2008). Three models of corporate social responsibility: Interrelationships between theory, research, and practice. Business and Society Review, 113(1), 1-41. doi:tps://doi.org/10.1111/j.1467-8594.2008.00311.x

Ghasemi Ali Abadi, M., Shakeri, A., \& Nassiri Aghdam, A. (2017). Introducing a model to measure the corporate governance index in usury-free banking. Journal of Money and Economy, 12(1), 55-71.

James, S. D. (2016). Strategic bankruptcy: A stakeholder management perspective. Journal of Business Research, 69(2), 492-499. doi:https://doi.org/10.1016/j.jbusres.2015.05.006

Lau, A. K., Lee, P. K., \& Cheng, T. (2018). An empirical taxonomy of corporate social responsibility in china's manufacturing industries. Journal of Cleaner Production, 188(7), 322-338. doi:https://doi.org/10.1016/j.jclepro.2018.04.010

Lee, C., \& Bruvold, N. (2003). Creating value for employees: Investment in training and education. International Journal of Human Resource Management, 14(6), 981-1000. doi:http://dx.doi.org/10.1080/0958519032000106173

Lopacinska, K. (2016). The merger of Geely automobile and Volvo car corporation as an example of the expansion of Chinese capital in the automotive sector. International Journal of Business and Administrative Studies, 2(6), 162-172. doi: https://doi.org/10.20469/ijbas.2.10001-6 
Moradi, M. (2016). Role of legitimacy theory and stakeholder theory in corporate social responsibility. Journal of Economic Studies, Financial Management and Accounting, 2(4), 174-186.

Thang, N. N., \& Fassin, Y. (2017). The impact of internal corporate social responsibility on organizational commitment: Evidence from Vietnamese service firms. Journal of Asia-Pacific Business, 18(2), 100-116. doi:https://doi.org/10 $.1080 / 10599231.2017 .1309617$

Turker, D. (2009). Measuring corporate social responsibility: A scale development study. Journal of Business Ethics, 85(4), 411-427. doi:https://doi.org/10.1007/s10551-008-9780-6

Wasike, C. N. (2017). Financial regulation as moderating, influence of corporate governance, institutional quality, human capital and firm size on financial institutions performance in Kenya. Journal of Administrative and Business Studies, 3(6), 292-304. doi:https://doi.org/10.20474/jabs-3.6.4 